He also finds it unnecessary either to administer the full opiate generally recommended, or to keep the bowels inactive for ten or fifteen days; neither does he enforce strict diet nor prolonged confinement to bed.

A. B-C, aged nineteen, married, was admitted on the 23rd of March. The patient, a healthy woman, rather tall and slender, but well-formed, had been delivered by a midwife of her first child about eight months previously. The labour was reported to have lasted nine hours, and not to have been usually difficult or severe, but the child was still-born. Ever since she had been unable to hold her water, except partially, while in the recumbent posture: The constant dribbling had caused much excoriation of the nates.

An examination per vaginam disclosed a circular opening in the anterior wall of the vagina, two inches from the os externum, about the size of a threepenny piece, communicating with the bladder, and readily admitting the end of the little finger. The edges of the fistula and surrounding tissues were free from induration and thickening.

The operation was performed under chloroform on the 30th March, about ten days after the termination of the menstrual period. The patient was placed on the left side, and the parts were exposed by means of the duck-bill speculvm. The operation of paring the edges of the fistula, which was freely performed with an angular-bladed knife, was, from time to time, suspended, in consequence of the somewhat abundant bleeding which ensued, although care was taken to avoid, as far as possible, the mucous membrane of the bladder. The wound was closed by means of seven sutures arranged transversely to the long axis of the vagina. Single silk ligatures were first inserted about half an inch from the margin of the incision, with a small needle curved to a semicircle, and held by a porte aiguille. Fine silver-wire sutures were then successively fastened to the end of each piece of silk, and drawn through, until the metal occupied the place of the silk; the wires were fastened by a single twist. Before the patient was removed from the table, the uretbra was dilated by passing first the little inger and then the forefinger into the bladder. She was kept in bed for forty-eight hours; though no opiate or other inedicine was given, she made no complaint of pain or distress, and slept well. She sat up on the third day, and could hold her water perfectly. The sutures were removed on the sixteenth day, when the patient left the hospital cured.

Ascites and Pelvic Hcematocele simulating Ovarian Dropsy; Recovery. - Mrs. P — aged twenty-three, married four weeks, was admitted $J_{\text {une }} 30 t h$, 1870, with enlargement of the abdomen, which was supposed to depend upon ovarian disease. The catamenia had commenced at the thirteenth year, and had always been regular, but during the last five years had been accompanied with considerable pain. Three months before admission she first noticed "a lump about the size of an egg" in the left iliac region, which had steadily increased, and since her marriage much mor rapidly than before. She had suffered considerable pain in the situation of the swelling, especially of late.

She had a pale, anxious expression, and was rather emaciated; the muscles were soft and flabby; the pulse 120, weak; the ton gue slightly coated; the bowels were regular; the appetite indifferent; micturition painful; the urine scanty and rather turbid. The abdomen was as large as at the full term of pregnancy; the distension being due to the presence of fluid. There was considerable bulging laterally, especially on the left side, and marked prominence above, from flatulent distension of the transverse colon. No anasarca.

On examination per vaginam and per rectum the uterus was found to be unaffected, but a fulness was perceived in the posterior cul-de-sac. Since the abdomen had become enlarged, she had suffered from slight cough and dyspncea, especially while in the recumbent position.

Two rear's before admission she had had rheumatic fever, followed by a tendency to palpitation of the heart of short duration. No signs of cardiac disease could be detected.

She was ordered purgatives of compound jalap powder about every other day; a diuretic mixture, containing acetate of potash, tincture of dioitalis, and spirit of juniper every fon hours; at bedtime occasionaily a dose of chloral hydrate (20 grains), to procure sleep; and milk diet, with brandy.

On the 5th of July the first mixture was changed for one of bitartrate of potash, decoction of broom, and spirit of juniper; and an occasional dranght of fetid spirit of ammonia and lavender was prescribed, to relieve distressing flatulence. Under this treatment her appetite improved, and the swelling of the abdomen decreased about two inches in circumference.

On the 20th the abdomen was ordered to be painted daily with the liquor iodi (B.P.), and a mixture of tincture of iron and quinine substituted for the other medicines.

From that time the enlargement of the abdomen diminished rapidly, and ultimately disappeared entirely, leaving nothing to be discovered, excepta small, firm elastic swelling in the posterior vaginal cul-de-sac, which had gradually become better defined as the ascitic fluid became absorbed.

The patient considered herself " quite well," and left the hospital on the 15th of August. She presented herself again in about a month's time, and was found to be in precisely the same condition, in general health and every other respect, as when she left.

\section{ROYAL SURREY COUNTY HOSPITAL, GUILDFORD.}

\section{A CASE OF TRAUMATIC TETANUS TREATED BY CHLORAL} HYDRATE.

(Under the care of Mr. EAgER.)

ALтночGн in this case the treatment was not ultimately successful, the chloral hydrate undoubtedly afforded the patient great comfort by procuring sleep, from which at one time he only awoke to attend to his natural wants; and, if the spasm which ensued on his being put to bed on the first day was a fair example of those which he had previously suffered, it certainly also for a time reduced the severity of the tetanic paroxysms.

The following notes are by Mr. Thomas Flower, housesurgeon.

James $R$ - aged twenty-three, a labourer, was admitted on August 1st. Twenty-four days before, whilst digging a pit, some earth fell on him, inflicting on his face a small wound, which was sewn up. He laid up for two days, and then attempted to resume work, but was unable to do much. The wound completely healed, and he improved until five days before aảmission, when he felt a slight stiffness and pain on both sides of the jaw, which had continued to become more severe.

On admission the jaws were firmly fixed; he had difficulty in swallowing liquids, and, occasionally, in breathing. After he was put to bed, he had well-marked risus sardonicus and opisthotonos; the pulse was 64 , the skin cool and moist, and the saliva flowed out of the mouth. He was ordered sixty grains of chloral hydrate immediately, and thirty grains every three hours afterwards ; milk and beeftea ad libitun; and six ounces of brandy every twenty-four hours.

Aug. 2nd.-Had a fair night; looks more comfortable; swallows better.

3rd.-Has had a good night and is sleeping continually, only waking up to take nourishment, which he seems to enjoy ; pulse 88 ; skin cool and moist; bowels open ; passes urine; jaws not relaxed.

4th.-Not so good a night; takes his nourishment well; attacks of spasms more frequent; pulse quicker.

5th.-Has most severe spasms of all muscles of body; respiration greatly impeded, and chieffy abdominal; he. becomes blue in the face when spasms are on; does not swallow fluids so well; pulse 100 ; passes urine.

6th.-Has continued to get much worse, and is not able to swallow anything. Enemata of beef-tea, brandy, and chloral hydrate were given, but without modifying the spasms, which occasionally threatened suffocation. $\mathrm{He}$ gradually became worse, and died at midnight. No postmortem examination was made.

A Large Dose of Chloral. - As much as 160 grains of the hydrate of chloral was lately given, by mistake, in one dose, to a middle-aged man in a hospital of this metropolis. Some alarm was felt, but no disagreeable symptoms occurred; the man slept well, and no unpleasant effects resulted. 